\title{
Using Crowdsourced Wikis to Teach an Online Undergraduate Course
}

\author{
John R. Fisher and Steven D. Allred \\ Utah Valley University
}

\begin{abstract}
A number of barriers exist that make using wikis in online teaching more challenging. Monitoring and correcting student actions is more difficult online than in a face-to-face classroom. Most students hesitate to edit and change other student writing and so incentives need to be used to get students to edit each other's work. Students should receive an orientation where they learn the purpose and benefits of wikis and receive instruction on how to use wikis. This study examined student use of wikis in an online assignment. As a course evaluation, students were asked to respond to five questions about their experience in using a wiki in the assignment. Conclusions were drawn about the practicality of using wikis in teaching online. Students affirmed that collaboration leads to learning and knowledge acquisition. By engaging in collaboration, learners observe and improve upon weaknesses or gaps in learning. Students learn from each other by examining and improving the work of others. Students also recognized that using wikis to develop documents is a valuable skill to take into the workplace. The study confirms much of the research on the topic of using wikis as a learning strategy. Also, the study shows that process is as important to learning as is outcome. The benefits of using wikis for learning are equally important as the final product produced.
\end{abstract}

Keywords: collaboration, crowdsourcing, emergency services, learning strategies, online learning, wikis

Fisher, J.R. \& Allred, S.D. (2020). Using crowdsourced wikis to teach an online undergraduate course. Online Learning, 24(3), 163-183. https:///doi.org/10.24059/olj.v24i3.2152

\section{Using Crowdsourced Wikis to Teach an Online Undergraduate Course}

Wikis have long been used for the collaborative creation of works. A prime example of a successful wiki is Wikipedia, which has taken over the business of ready references, replacing big names like The Encyclopedia Britannica and World Book (Rothman, 2016). Wikis are a valuable business tool, permitting collaboration and creation of works on the job (Bolisani \& Scarso, 2016; Grace, 2009; Ojala, 2008). In the learning field, studies have shown their successful inclusion in face-to-face classes (Hubble, 2011; Roussinos \& Jimoyiannis, 2013). With other social media, 
wikis are particularly suited for online learning (Abdelmalak, 2014; Zgheib and Dabbagh, 2020). This paper explores the use of wikis in online learning.

Most young Americans use Wikipedia. Among those in the age range of most university students (18-29 years old), Pew (2011) reports 62\% turn to Wikipedia, despite it not being acceptable to cite Wikipedia as a source in academic papers (Infeld and Adams, 2013). Wikipedia has become the initial source students check to get an understanding and find sources for topics in their areas of study. Wikipedia is an example of a crowdsourced document.

Crowdsourcing is the process of obtaining information from a large number of people, usually using the internet (Howe, 2008). Many applications rely on crowdsourced information to function and provide on-demand services. One of these is the wiki, which uses the input of volunteers to create and improve contributions to a crowdsourced document (Leal et al., 2019).

A wiki is a collaborative website where many people contribute to the development of content online. In addition to making their own contribution, individuals can edit and add to each other's work. Wikis operate on the Aristotelian principle that the whole is greater than the sum of its parts, the modern concept of synergy. A search of the literature supports the following claims about wikis (Palomo-Duarte et al., 2014; Page \& Reynolds, 2015; Trocky \& Buckley, 2016). Wikis help student writing skills, group collaboration, and knowledge acquisition. Student outcomes are improved, by providing a context for learning. Through cognitive and social engagement, wikis support the development of a community of learners.

Yarbrough (2018) summarized the benefits of wikis: (a) engagement and collaboration, (b) learning from other students, (c) group work, (d) community building, (e) critical thinking, (f) reflection, (g) construction of knowledge, and (h) extending learning beyond the classroom.

As the focus on higher education learning has shifted from knowledge to skills, some of these skills, particularly interpersonal skills, are difficult to assess and to develop. According to Palomo-Duarte et al. (2014) some of the skills can be assessed objectively through the use of wikis. They provide as examples: collaborative writing, conflict resolution, group management, and leadership. This new environment, Page and Reynolds (2015) claim, requires learning experiences that develop collaborative and mediated social writing practices. They offer wikis as a way to meet these needs. However, while wikis appear to provide suitable tools for teaching, Trocky and Buckley (2016) indicate uncertainty as to their effectiveness in achieving student learning outcomes. They found that, as an instructional strategy, wikis aid students in learning various skills and gaining new knowledge. Wikis improve writing skills, collaboration, knowledge acquisition, and serve as a centralized repository. Wikis appear to focus more on process goals rather than learning outcomes.

In this article, we explore the use of a wiki in online learning. As a data source, we examined student success using wikis in an online crisis communication course for emergency services students. Students were assigned to develop guidelines for preparing a crisis communications plan using a wiki process. Each student contributed original content and was asked to edit the work of other students.

\section{Problem Statement}

The purpose of this study was to evaluate the use of a wiki in an online course so as to determine how the wiki assignment design could be adapted to be more effective and provide greater learning. 


\section{Research Questions}

Five research questions were considered:

1. How can a class wiki contribute to the learning of students in the class?

2. Was the class wiki helpful in a student's own learning about crisis communication plans?

3. Did students read the contributions of other students and learn from their work as they prepared their own submission for the crisis communication plan?

4. What kinds of revisions did students make on the work of other students?

5. What incentives would get students to change and edit or comment and provide feedback to other students using the wiki process?

\section{Review of Relevant Literature}

The literature review that follows supports the wide use of wikis in teaching face-to-face and online courses. No articles were found where wikis were studied in teaching either face-toface or online courses in the emergency services.

\section{Collaboration and the Wiki}

Collaboration is an important process outcome of learning. On-the-other hand, collaboration benefits learning. Wikis are a form of collaboration that the Internet enables. The Internet also facilitates other collaborative learning and communication through forums, email, video conferencing and chat rooms. However, according to Oskoz and Elola (2014), wikis make collaborative learning "more efficient." They allow people to work together (p. 144). By engaging in collaboration, students notice gaps in their learning. The students learn from each other by observing the others' contributions and noting and improving upon other's deficiencies. Wikis also allow peer-to-peer writing assistance. Wikis encourage peers to be teachers. Students become both learners and instructors (Oskoz and Elola, 2014, p. 145).

Collaboration is a key aspect of community learning (Woolley \& Ludwig-Hardman, 2000). Abdelmalak (2014) studied student reaction to various social media to determine which were most important in creating an online learning community. Students indicated that Google Docs, wikis, blogs, and Twitter helped develop a learning community while Skype did not. Wikis and Google Docs were deemed to have the most impact. The researcher determined that faculty should use a variety of social media to support learning communities and student interaction and communication.

Collaboration using wikis has been successful in second and foreign language learning. (Sykes, Oskoz, and Thorne (2008) point out the various online tools that could be used in transforming traditional approaches for second language education. Zou, Wang, and Xing (2016) studied the use of wikis by students learning English in China and Chinese in the United Kingdom. Students corrected each other's language errors using a wiki. Li and Chu (2018) used a wiki-based collaborative process writing pedagogy (WCPWP) to help the teaching and learning of Chinese writing among mainland Chinese upper primary school students. Collaborating through wikis had positive effects on students' writing ability, writing attitudes, collaboration, reading, and oral expression. They found collaboration benefits learning. 
He and Yang (2016) found that using wikis promoted communication and collaboration in teams. While most team collaboration occurs in face-to-face meetings, wikis are particularly suited to online team development.

\section{Wikis and Online Learning}

Rather than repackaging face-to-face content, online course developers must provide unique value to keep the quality of their offerings high. Also, well-designed online courses have the unique ability to be student-centered and engaging. Furthermore, online courses can easily adapt to and incorporate emerging technologies and innovative computer applications.

"Student engagement is critical to student learning, especially in the online environment, where students can often feel isolated and disconnected," (Dixson, 2015). A wiki-based course design responds to online concerns of isolation because it creates a student-centered learning environment (Hu and Johnston, 2012). It can both engage and empower students and encourages equitable and quality participation while providing flexibility for student learning (Qian and Erik, 2012). Use of social media learning activities support cognitive processes and ensure student engagement in knowledge acquisition (Zgheib and Dabbagh, 2020). Because of the nature of online studies, faculty have difficulty developing relationships with students and vice versa. Wikis develop teacher to student and student to student relationships (Yarbrough, 2018). Online classes may not suit every learning style. Park and colleagues (2010) suggested use of wikis as a means of crossing these learning styles.

Sharp and Whaley (2018) identified benefits and challenges associated with wikis. Adult learners in their study recognized the collaboration potential of wikis and the benefits of knowledge acquisition and giving and receiving feedback. They viewed wikis as a "kind of brainstorming process" and better than a forum because they were able to edit and add to others' comments (p. 89). Adult learners had a number of doubts and uncertainties going into the wiki project. Most were unfamiliar about the how and function of wikis and some lacked technical capabilities. Others were concerned about the academic acceptability of wikis and some viewed them as not being a productive use of class time. Some were concerned about "learning to work as a team to co-construct content" and others were concerned about group grades (p. 89).

Biasutti (2017) compared the usage of forums and wikis in online teaching. The results showed that inferencing, evaluating, organizing, and supporting characterized forum discussions while wikis encouraged mainly processes of producing and developing. Forums were useful for discussing, sharing ideas while wikis were used for developing a common collaborative document. Forums were easier to access than wikis, while wikis required more time and were more difficult to use than forums. While forums and wikis had different characteristics, Biasutti concluded that using both strategies could provide complementary functions, allowing scaffolding of student learning.

Wiki-based online courses should use a wide-range of technology tools and innovative class activities (Qian and Erik, 2012). Yarbrough (2018) showed how wikis can be used for course evaluations and online quizzes. She found using rubrics helped clarify assignment requirements. Zgheib and Dabbagh (2020) suggested using wikis and blogs as learning management systems. They pointed out that faculty need training and support to incorporate social media learning activities into online course design. 


\section{Other Uses and Findings about Wikis}

Wikis have been used in many fields to create work through collaboration. In an early use of wikis, Hasan and Pfaff (2006) used the technology to improve employees' interaction with corporate knowledge. Evans and Moore (2011) used chemistry software for the creation of interactive chemistry content on the internet. Ertmer et al. (2011) designed an international wikibased collaboration in an introductory educational technology course of 346 students in which students created wiki chapters about the educational uses of specific Web 2.0 tools. Survey results showed significant changes in confidence and perceived value, while qualitative results provided insights into students' perceptions of critical project components.

The University of North Carolina at Pembroke (UNCP) uses student-generated content to create encyclopedia entries for the Online Encyclopedia of Criminal Justice (cjencyclopedia.com) on topics related to criminal justice and related fields. Students edit, revise, and organize content using wiki software (Sener, 2019). The U.S. Army constructed a wiki-based system to develop plans and deploy procedural knowledge in emergency situations (Wickler, Tate, \& Hansberger, 2013). In Canada, wikis were used as knowledge translation tools to help health professionals implement best practices in acute care (Archambault et al., 2012). Shih, Tseng, and Yang (2008) found wikis can be used to develop teaching materials quickly for online courses.

\section{Teaching Students to Use Wikis}

Stoddart, Chan, and Liu (2016) developed a general framework to assist instructors in setting up wiki projects for language learning. The suggestions they made were aimed at providing an environment that fosters student satisfaction, motivation, and learning. Here are eight steps they use in teaching using wikis: (a) introduce the concept of collaboration, (b) teach how to use the wiki software, (c) introduce the assignment, (d) break the assignment into smaller parts, (e) establish feedback procedures, (f) teach a critique process, (g) setup a timetable for group critiques, and (h) provide post-project critiques.

From a study of learning outcomes of non-English speaking, computer-savvy students in an international marketing course, Hewege and Perera (2013) confirmed that wikis promoted collaborative learning, organic discussions, and independent thinking. In addition, they found that students adapted well and with little difficulty to wiki-based pedagogy. While students engaged in the wikis at different levels and sometimes discussions stagnated, the researchers learned that aligning assessment with learning activities helped engage the students. To keep students enthusiastically engaged in wiki discussions, wiki-based activities must be embedded into other learning activities.

During the 2010-2011 academic year, the Wikimedia Foundation launched WikiProject U.S. Public Policy, to recruit experts and students to help improve Wikipedia content. Infeld and Adams (2013) used the Wikipedia project to examine the learning that occurred by using opensource, wiki-based assignments in policy analysis courses. The researchers had their students take Wikipedia training on how to use a wiki and then required them to find and add content to Wikipedia articles related to policy analysis topics discussed in their classes and based on a major policy paper they wrote. Infeld and Adams (2013) found they had to be explicit in describing how the exercise was relevant to the study of public policy in order to convince all students of the value of the project. Students found that using Wikipedia was engaging and allowed them to test their knowledge by contributing to the public thought (p. 456). 
Rott and Weber (2013) provided a framework to effectively structure a collaborative and cooperative student research assignment using a wiki site as a writing platform. Students learned how to post text and pictures and to productively collaborate on composing, revising, and editing. In their early attempts to use wiki, students did well in composing and sharing information but were hesitant in critiquing or changing the work of other people. To make students aware of the revision process, the researchers provided actual examples of student feedback and changes made from previous classes. They also showed how students would be evaluated using rubrics and given a grade for their revisions to others' work.

Prior familiarity with the internet gives students a step up when learning to use wiki and other social media. He and Yang (2016) found wikis are used more frequently in information technology courses, probably because technology students are more ready to experiment with new technologies. In a study that included 58 postgraduate students, Page and Reynolds (2015) found that while students are heavy users of social media, they have not learned to work collaboratively in groups or in social media contexts (p. 1004). Prior to the project, students had been heavy consumers of wikis, but had had little actual experience in creating, reviewing, or editing wikis. They found that students who had less experience with the web participated less in the wiki project (p. 1007).

Chu et al. (2017) found that discipline of study factored into students' perceptions and actions with wikis in project-based learning. English language students regarded wikis as extra workload while information management students viewed wikis as efficient tools for learning. Mechanical engineering students avoided using wikis if they felt little relationship existed between the learning goal and collaborative learning. The study showed significant differences existed in motivation and knowledge management, affecting level of participation and involvement in wiki processes. The factors that influenced performance were previous learning experiences, technical backgrounds and the relationship between learning goals and collaborative learning.

\section{Methods Used to Study Wikis}

Researchers used a combination of mixed methods, both quantitative and qualitative, to study the use of wikis in learning. Park et al. (2010) developed the Perception of Wiki Survey to determine students' perceptions of the value of the technology. They also used the FelderSilverman Index of Learning Styles to study students' learning style preferences, based on the notion that a student's choice to pursue one career over another, and eventual success or lack of success in that career, may relate to their personal learning style and the learning demands of that discipline.

Palomo-Duarte et al. (2014) compared seven case studies conducted in computer science courses of two Spanish universities: Cádiz and Seville. They used automated tools to assess student interactions, measuring different settings, durations, milestones, contribution sizes, weights in the final grade and assessment methods. Page and Reynolds (2015) used data drawn from multiple sources collected before, during and after to evaluate their project. The Li and Chu (2018) study was conducted in a primary school in Shenzhen, China, and divided into three research phases spanning one and a half years (three semesters). Both quantitative and qualitative methods, including online wiki documents, a course feedback questionnaire, observations, interviews, and a teacher's questionnaire, were used to collect data.

Hewege and Perera (2013) used a qualitative research methodology supported by the Nvivo data analysis software. The researchers used a triangulated approach to collecting data, which 
included the identification of themes from 30 student assignments, student description of positive and negative experiences with wikis, and in-depth interviews of teachers.

Dixson (2015) developed an Online Student Engagement Scale (OSE) which measures online student learning experience. She noted that student engagement is supported by two types of student behaviors: application and observation learning behaviors. Examples of application learning behaviors are posting to forums, writing emails, and taking quizzes and observational learning behaviors are reading emails, reading discussion posts, viewing content lectures and documents. Dixson found the OSE correlated positively with application learning behaviors.

Biasutti (2017) used both quantitative and qualitative analyses to compare forums and wikis as tools for online collaborative learning. A quantitative comparison of forums and wikis was developed applying the coding scheme based on the following indicators: (a) inferencing, (b) producing, (c) developing, (d) evaluating, (e) summarizing, (f) organizing, and (g) supporting. The qualitative aspects were assessed using an open-ended questionnaire for collecting participants' perspectives on the functionality of the collaborative tools.

Sharp and Whaley (2018) analyzed pre- and postquestionnaire data from graduate students using statistical analysis to explore perceptions of usefulness and ease of use of wikis. Qualitative data were analyzed using descriptive analysis techniques to explore perceptions and themes related to benefits and challenges with wikis.

\section{Methods}

Over a four-year period, emergency service students were required to contribute to a class wiki as part of an assignment to prepare guidelines for developing a crisis communication plan. Students submitted an initial piece of writing on a self-selected topic in the area of study. They were asked to read other people's submissions to avoid duplication and to expand their own submissions. In addition, they were asked to revise other students' work based on their own research and as a means to improve the overall finished product. Over time the course instructors observed that students were making few, if any, revisions. The instructors did the literature review and study to determine how to improve the outcomes of the wiki assignment. Their aim was to increase student motivation to make revisions and overall student satisfaction in using the wiki process.

During the course evaluation at the end of the most recent class students were asked to respond to five questions. Seventeen of 21 students answered the questions. Ten of the respondents were male; seven were female. The respondents were representative of the students in the emergency service program. Eight of 10 males work for police or fire agencies; two women work for agencies. Ten students are studying emergency leadership; six students are studying emergency management. Three students are from out-of-state. The average age of male students is 29 and female students is 26 . Three students are under 21 . To maintain anonymity respondents were identified by initials, the first indicating the person was male $(\mathrm{M})$ or female $(\mathrm{F})$. The five questions were:

A. How can a class wiki contribute to the learning of students in the class?

B. Was the class wiki helpful to your own learning about crisis communication plans? 
C. Did you read the contributions of other students and learn from their work as you prepared your submission for the crisis communication plan? How were they useful?

D. Did you edit or change the work of any other students? What changes did you make?

E. What incentives or means would get students to change and edit or comment and provide feedback to other students using the wiki process?

The student responses were analyzed using descriptive techniques, allowing the researchers to explore the perception and themes about the benefits and challenges of using wikis (Sharp and Whaley, 2018). A qualitative approach was used because it provides rich data. Rich data (also described as thick description) is important when the number of respondents is limited as in this study. "Thick description seeks to present and explore the multifaceted complexities of the situation being studied" (Marx, 2008). Rigor is measured by saturation. As data within a category overlaps, understanding of the phenomenon becomes stronger. Researchers realize saturation as they become aware that the data comprehensively or completely describes the phenomenon. Also, they note that responses begin to be repetitive, duplicating topics and stating the same thing although in different words (Morse, 2015). It is through this process that themes are developed.

Content analysis was used to examine the student submissions about crisis communication plans (Bengtsson, 2016). Thematic analysis was used to study student responses (Castleberry and Nolen, 2018; Kannaley et al, 2019; Talbot et al., 2020). The literature review was used to develop an initial set of codes. Codes were added as new themes became evident. Researchers used the codes to independently review the student comments. After the student comments were coded, the first researcher reviewed all quotations from each category and assigned the quotations to themes. All coded content was included for analysis and quotes were chosen that best supported the themes. As themes were developed and, based on the literature review, recommendations for changes and improvements to the wiki assignment were made. These recommendations are proposed for general application in the use of wikis in online learning.

\section{Results}

The literature review suggests a number of possible themes. Wikis encourage people to work together. Collaboration benefits learning, helps develop writing skills and leads to knowledge acquisition (Trocky and Buckley, 2016; Li and Chu, 2018). They encourage peer-topeer writing assistance (Oskoz and Elola, 2014). They engage and empower students (Qian and Erik, 2012). As the student responses to questions were examined, some of these themes were validated; others were not. Table 1 shows themes generated from the Literature Review and Codes that were used to examine student responses to the questions. 


\section{Table 1}

\section{Codes Generated from the Literature Review}

\section{Literature Review Topics}

construction of knowledge

wikis make learning more efficient, identifies gaps in learning, students learn from each other, get writing assistance

wikis create an online learning community; community building

fosters satisfaction, motivation, learning

collaboration in language learning

correcting each other's language errors

writing ability, attitude, reading, expression used synchronously and asynchronously online, hesitant to critique or change others' work, provided grading criteria, rubric collaborative learning, organic discussions, independent thinking

students added to Wikipedia, describe relevance, contribute to public thought

impact exam performance, web familiarity affected participation, consumers not creators

communication and collaboration in teams

technology students willing to experiment; differences in motivation and knowledge management among disciplines student engagement critical

use several social media tools for engagement, faculty need training and support

use wikis to develop teaching materials

encouraged equitable, quality participation, flexibility for student learning

student-centered

learner engagement, promote thinking, knowledge acquisition, giving and receiving feedback, brainstorming, wikis better than forums,

unfamiliar, lacked technical skills, academic acceptability, not wise use of time, working as team, group grades

crossing learning styles

forums best for discussing, wikis for production; extending learning beyond the classroom

build relationships online

provide course evaluations
References

Trocky \& Buckley, 2016;

Yarbrough, 2018

Oskoz \& Elola, 2014

Abdelmalak, 2014;

Yarbrough, 2018

Stoddard, Chan \& Liu, 2016

Sykes, Oskoz \& Thorne (2008); Zou, Wang \& Xing, 2016

Zou, Wang \&Xing, 2016;

Yarbrough, 2018

Li \& Chu, 2018

Rott \& Weber, 2013

Hewege \& Perera, 2013;

Yarbrough, 2018

Infeld \& Adams, 2013

Page \& Reynolds, 2015

He \& Yang, 2016; Yarbrough, 2018

He \& Yang, 2016; Chiu et al., 2017

Dixson, 2015; Yarbrough 2018

Zgheib \& Dabbagh, 2020

Shih, Tseng \& Yang, 2008

Qian \& Erik, 2012

Hu \& Johnston, 2012

Sharp \& Whaley, 2018

Sharp \& Whaley, 2018

Park et al., 2010

Biasutti, 2017; Yarbrough, 2018

Yarbrough, 2018

Yarbrough, 2018
Codes

knowledge

learning, gaps, collaboration, help each other

community

satisfaction, motivation, learning

collaboration

help each other, learn from each other communication

online, hesitancy, tools

collaboration, critical thinking, reflection

structure, relevance

outcomes, participation, collaboration, create

teams

area of study

engagement

engagement, tools, faculty training

faculty training

participation, flexibility

student-centered

engagement, critical thinking, knowledge, critical thinking, reflection, feedback, forums skills, acceptability, value, team, grades

learning styles

forums, production; application

relationships

evaluation 
As student comments were examined, grouped, and analyzed for themes (Castleberry and Nolen, 2018), it became clear that themes would fall into two major categories: benefits and challenges (Sharp and Whaley, 2018). Challenges were deemed to be process-related. The following is a list of the themes, categorized as benefits or challenges, and coding used to identify themes within student comments. The themes are matched to the student questions. Challenge themes are stated as positive actions, rather than negative responses.

The tables that follow show the results from the thematic analysis. They were developed using the following procedure.

1. Using a Microsoft Excel spreadsheet, student responses were grouped under the five research questions.

2. Responses were then coded, using the codes generated from the review of literature about wikis (see Table 1). To generate the codes the literature was summarized into topics.

3. The responses were then summarized and grouped under the questions and codes.

4. Themes were developed from the summaries of student responses. They were categorized as either Benefits or Challenges and numbered.

5. The results were then organized in tables, one table for each theme. The tables show the topic, codes, references, paraphrasing or quotes of student responses, the research questions, and finally themes.

\section{Table 2}

Topic: Learning and Knowledge Acquisition

Codes: knowledge, learning, gaps in knowledge

References: Trocky \& Buckley, 2016; Yarbrough, 2018; Oskoz \& Elola, 2014; Stoddard, Chan \& Liu, 2016; Sharp \& Whaley, 2018

\section{Student responses:}

In response to Question A, respondent FL wrote that wikis provide students a greater range of information instead of students using the same four or five articles. MJ stated the wiki benefits class members by having high-quality information about a topic in one place. By everyone adding to the wiki, all students learn. MJE stated learning together instead of alone students have more of an incentive to learn and discuss as well as provide meaningful information. FS stated, by looking at the work of other students, students gain better understanding.

MR suggested that "a class wiki can be beneficial by providing a running document of knowledge that is able to include multiple former classes and different perspectives on understanding points of view."

Eleven people found the wiki helped them learn about crisis communication plans (Question B), while four indicated it did not. Two people did not respond to Question B.

MR stated, "I found the wiki helpful to me learning about my crisis communication plan, not only for some general guidance of layout, but also overall types of information being presented." MS wrote, "It gave me a good understanding of the different parts of communication and disaster response.

Theme: Benefit 1-Wikis provide information that leads to learning and knowledge acquisition. 
Table 3

Topic: Viewpoints

Codes: feedback, viewpoints

References: Sharp \& Whaley, 2018; no reference for viewpoints

Student responses:

In response to Question A, respondent FJA indicated she felt contributions helped others increase their knowledge from other points of view. MR also identified varying points of view as a benefit to wikis. FS indicated that taking part in the class wiki made it so she could understand the information from many different angles.

Theme: Benefit 1a-Wikis provide many viewpoints.

Table 4

Topic: Collaboration

Codes: collaboration

References: Oskoz \& Elola, 2014; Yarbrough, 2018; Sykes, Oskoz \& Thorne (2008); Zou, Wang \& Xing, 2016; Hewege \& Perera, 2013

\section{Student responses:}

In answer to Question $\mathrm{A}$, respondent $\mathrm{MB}$ identified collaborating as a way of contributing to class learning. FL indicated that collaborating made the assignment feel like "a real-world professional project." FL also wrote the wiki benefited the class because the project can have many contributors but one overall message. FK stated the wiki allowed the class to work together as a team.

\section{Theme: Benefit 2-Wikis encourage collaboration.}

Table 5

Topic: Sharing information

Codes: sharing, help each other, feedback

References: Oskoz \& Elola, 2014; Sharp \& Whaley, 2018

Student responses:

In response to Question A, respondent $\mathrm{MZ}$ compared the wikis to reading summaries, another online tool used in the class. "The wiki assignment was informative in the same manner the reading summaries were. It allowed us to share information that can be used as a model for building an effective communication plan in a disaster."

MZ identified sharing information as a benefit of wikis. MS saw sharing knowledge and experience by like-minded individuals as important to learning.

$\mathrm{MJ}$ indicated it was an easy way to find needed information. (Question C)

Theme: Benefit $2 a$-Wikis allow students to share information. 
Table 6

Topic: Engagement

Codes: engagement, participation

References: Dixson, 2015; Yarbrough, 2018; Zgheib \& Dabbagh, 2020; Sharp \& Whaley, 2018;

Qian \& Erik, 2012

Student responses:

Respondent FM felt the wiki got everyone involved. This was particularly important since the class was online (Question A).

Theme: Benefit $2 b$-Wikis increase student involvement and engagement.

Table 7

Topic: Extending learning beyond the classroom

Codes: application

Reference: Yarbrough, 2018

Student responses:

In answer to Question B, respondent FL saw the practical value of wikis, which has application in the workplace where people cooperate together on a document. "I think the wiki was a good way to see how crisis communications plans are created and what they look like. There is a lot of needed information, and it is all very different, but necessary. Many people will be involved in a crisis communication plan; the wiki was a cool way of simulating that with the class."

Theme: Benefit 3-Wikis provide practical skills that can be used in the workplace.

Table 8

Topic: Production of content

Codes: production

Reference: Biasutti, 2017

Student responses:

For Question B, respondent FS wrote about choice of topic for the wiki. "I understand that not everyone can be a specialist in their different areas of expertise, but it is amazing to see what others know about or what they gravitate towards."

MD found the "other categories" important but felt the topic he chose was "redundant."

Generally, people who read the other wikis found them useful in writing their own contributions and in understanding crisis communications (Question C). MR wrote, "I read several of the other student's wikis and found them useful as additional perspectives to give me some ideas on how to expand the information I also provided."

FL indicated, "I did read the contributions of the other students and used the information to get a feel for how they viewed the project and the type of information they submitted. I tried to add information that had not already been stated. Some of my classmates seemed to have experience with crisis communication plans and their input was very clear and valuable to the piece as a whole."

Theme: Benefit 3a-Wikis help students develop their own content. 
Table 9

Topic: Wikis used for production

Codes: production, application

References: Biasutti, 2017; Yarbrough, 2018

Student responses:

"The class wiki, which I was able to read, contribute to, and edit, helped me understand crisis communication plans much better," wrote MJE in response to Question B. "I was able to see what others were learning about the plans and implement my own research all under the same document which was very efficient and useful."

Theme: Benefit $3 b$-Wikis can be used efficiently to develop documents.

Table 10

Topic: Learning how to do wikis

Codes: skills, structure,

References: Infeld \& Adams, 2013; Sharp \& Whaley, 2018

Student responses:

As a response to Question A, respondent MF wrote that wikis were new to him, but as soon as others started adding information, he knew what to do and the wiki made sense to him.

In answer to Question B, FM indicated, "It was very helpful to me because this was the first class I've taken involving emergency planning/preparedness so this was all so new to me and being able to have others contribute to mine and see others plans as well helped me see where I could improve and how to think differently that would help me become a better planner and communicator."

MZ stated, "It helped me understand a little more in what subjects one might need to think about when developing a communication plan."

MJ wrote, "It was new and ... it made us work harder in a good way."

\section{Theme: Challenge 1-Help students learn a new skill using wikis.}

Table 11

Topic: Skill building

Codes: skills

Reference: Sharp \& Whaley, 2018

Student responses:

Respondent FJ saw the wiki as "another tool" that "did not provide anything except some new method of sharing to learn." In response to Question B, she stated that "the amount of time it took to learn how to use a new system to share information took away from the importance of how to conduct crisis communications."

In speaking generally about the class, MS stated, "The only problem I ran into while in this course was the wiki page. The wiki page just didn't feel too user friendly for me, and had a hard time getting my portion in there."

One person (in answering Question C) found wikis hard to understand and two others felt other approaches would have been more effective for learning. FJA indicated that she read other 
people's work but found the information hard to understand. "I ... was not sure how to translate [it] to a communication plan.”

MF would have preferred a discussion over doing the wiki. "In my opinion, I found the class wiki to be a bit messy compared to just having this assignment become a regular discussion."

In response to Question E, FJA stated, "I do not think wiki is something that most students find friendly. I think the idea is good but it's too much information to scroll through without guidance."

\section{Theme: Challenge 2-Focus on wikis as a skill not just a content tool.}

Table 12

Topic: Purpose

Codes: hesitancy, relevance, value, prior training

References: Rott \& Weber, 2013; Infeld \& Adams, 2013; Sharp \& Whaley, 2018, Page \& Reynolds, 2015

Student responses:

Only two people made changes to other student work. In response to Question D, respondent FS indicated, "I made a few changes, but I wish that I would have made more changes and got to understand the system." MJE indicated that most of what he edited in the document was grammatical errors. Twelve students indicated they did not make changes.

In response to Question B, FS wrote, "I loved using the class wiki. At first, I was hesitant about it because I didn't want to have to post work right next to another person's work or in the middle of it. However, as it unfolded, I loved the opportunity to see what other people thought on my topic that I shared or even completely opposite things.

To Question C, MB indicated, "There can be critical disagreements and discussions about posts, but the editing and changing nature of a wiki is too free flowing for my personal preference."

Other people either thought there was nothing to change or felt inadequate to make changes. FL wrote in responding to Question D, "I felt like all of my classmates provided very thorough and accurate information. I did not notice any spelling or grammar errors, otherwise I would have edited them."

MF indicated he felt "it was not appropriate to edit other people's work besides my own, but there could have been a few adjustments made here and there." FK wrote, "I don't think anyone wants to edit someone else's work."

MB indicated he did not change or edit the work of other students, because "it is clear when students actually put in an effort and when they did not." He added that "students trying to contribute helped the wiki as a whole, but the students who simply contributed for a grade really didn't leave quality enough content to even add to."

In response to Question $\mathrm{E}, \mathrm{MZ}$ wrote that he felt people should be left to decide if they will edit other wiki contributions. MR stated, "I personally don't know that I would actually want to edit another student's wiki that is published based on their personal perspective and I wouldn't feel right modifying that."

\section{Theme: Challenge 3-Help students see the value of doing revisions.}


Table 13

Topic: Incentives

Codes: incentives, value

References: Sharp \& Whaley, 2018; No references for incentives

Student responses:

Only four students gave positive suggestions in response to Question E. They suggested extra credit or making editing a part of an assignment. Six responded negatively.

Respondent FL stated, "I think students are highly incentivized through points and extra credit to bolster their grade. I think offering points for extra feedback and comments would work well." MJ agreed that giving extra credit might get people to edit or change wikis.

FS wrote, "With school, I believe that the best incentive is grades. If there is some sort of extra credit, I would have done it."

FMA stated that she would edit other's work only if it was required as part of the assignment.

Theme: Challenge 4-Provide students incentives for doing revisions.

Table 14

Topic: Attitude

Codes: satisfaction, motivation, forums

References: Stoddard, Chan \& Liu, 2016; Infeld \& Adams, 2013; Biasutti, 2017; Sharp \& Whaley, 2018

\section{Student responses:}

Two students made negative comments to Question A. FJ indicated the wiki did not contribute to her learning. FMA found the wiki assignment no different than other assignments in the class.

In response to Question B, four people indicated they did not find the wiki useful. MF wrote, "There was a lot to learn from what everyone shared, but I didn't find this to be very effective." FJA indicated that the wiki was "not particularly" helpful, because "it was too overwhelming for me personally." As a response to question E, MB stated that he would rather do discussions because "the lack of effort makes a course wiki a difficult thing."

In response to Question C, MW wrote, "For me I used other sources even though I probably should have looked at the class wiki more often." Although he did not use them as resources, he thought they would have helped.

A number of people did not look at other people's wikis or looked at them minimally.

Theme: Challenge 5-Help students gain a positive attitude about wikis. 


\section{Discussion}

For most students, the wiki assignment in the emergency services course was their first exposure to creating and editing wikis. Their experience with wikis likely came as consumers of Wikipedia and other wiki websites (Page \& Reynolds, 2015). While students had not studied or read a lot about wikis, in their responses to questions, they were able to identify some of the same benefits and challenges pointed out in the literature. Themes are very closely related to each other and show a crossover of information.

Table 2 lists the themes which emerged from student responses to questions about their experience with wikis. The questions students responded to are listed in the far-right column.

Table 15

Benefit and Challenge Themes Matched to Questions

$\begin{array}{lll}\text { Benefit or } & \text { Theme } & \text { Question } \\ \text { Challenge \# } & & \end{array}$

\begin{tabular}{lll}
\hline Benefit 1 & $\begin{array}{l}\text { Wikis provide information that leads to learning and } \\
\text { knowledge acquisition. }\end{array}$ & A, B \\
Benefit 1a & Wikis provide many viewpoints. & A \\
Benefit 2 & Wikis encourage collaboration. & A \\
Benefit 2a & Wikis allow students to share information. & A \\
Benefit 2b & Wikis increase student involvement and engagement. & A \\
Benefit 3 & Wikis are a useful skill to take into the workplace. & B \\
Benefit 3a & Wikis help students develop their own content. & B, C \\
Benefit 3b & Wikis can be used efficiently to develop documents. & B \\
\hline Challenge 1 & Help students learn a new skill using wikis. & A, B \\
Challenge 2 & Focus on wikis as a skill not just a content tool. & B, C, E \\
Challenge 3 & Help students see the value in doing revisions. & B, C, D, E \\
Challenge 4 & Provide students incentives for doing revisions. & E \\
Challenge 5 & Help students gain a positive attitude about wikis. & A, B, C, D, E \\
\hline
\end{tabular}

In this study, learning and knowledge acquisition were identified as benefits as was collaboration (Oskoz and Elola, 2014; Hewege \& Perera, 2013; Yarbrough, 2018). Collaboration appears to be closely tied to learning. $\mathrm{Li}$ and $\mathrm{Chu}$ (2018) found collaborating through wikis positively impacted learning. Students in this study indicated that "working together students have more incentive to learn" and they gain better understanding by looking at the work of other students. Looking at various points of view helped increase knowledge, one student wrote. Learning improved by understanding information from "many different angles." 
A major disadvantage of online education, according to some scholars (Kirkwood \& Price, 2013), is that students study alone. Collaboration in online courses using wikis and other social media allows students to "work together as a team." Sharing information was seen as a benefit of wikis. One student wrote, "The wiki assignment ... allowed us to share information that can be used as a model for building an effective communication plan in a disaster."

As some students pointed out, wikis are a good way to "extend learning beyond the classroom" (Yarbrough, 2018) into the workplace. The wiki assignment allowed the students "to see how crisis communications plans are created and what they looked like." The assignment felt like "a real-world professional project," wrote a student. Wikis apply easily to the workplace because they help students develop their own content and can be used efficiently to develop documents.

Students found it hard to learn to use wikis; they also found the amount of information overwhelming and sometimes hard to understand. Infeld and Adams (2013) used Wikipedia as the platform for student submissions. They found they had to be explicit in describing how the exercise was relevant to the study topic in order to convince students of the value of using wikis. Orientation is important in using wikis for teaching. Before the assignment students need to learn the purpose and how of using wikis. During the assignment, it is also necessary to monitor student progress. While this is harder online, it is equally important as it is in a face-to-face class.

While many students saw the value of the wiki and extolled its virtues as a learning tool, few of them used it to its full extent by adding to or revising other student work. Rott and Weber (2013) found in their early efforts using wikis that students did well in composing and sharing information but were hesitant in critiquing or changing the work of other people. This is a finding of this study as well. Some students were hesitant to revise the work of other students. Students need reasons for editing and revising the work of other students. Instructors should help students see the value of doing revisions as not only a way to help other students, but also improve the document. Assignment instructions and wiki training should point out that other students benefit and appreciate help with writing and content. In addition, points as part of the assignment or extra credit should be given for editing others' work. The editing process must also be easy for the students to use and provide an editing history. Wiki software, Google Docs, and now most learning management systems provide for easy editing and editing histories.

Some students did not look at other people's work or did so minimally. Four people indicated that they did not find the wiki useful. Some saw learning to use wikis as inhibiting their learning about crisis communications plans. They viewed the wiki as a means to an end as opposed to being an end in itself. These problems could possibly be overcome by providing training about how to do wikis and by emphasizing the value of wikis in an orientation. Area of study and learning style may be factors in negative attitudes toward wikis in this study. Chu et al. (2017) found significant differences in motivation and knowledge management among students in language studies, information management, and engineering. Students in information management had the best attitude because of previous learning experiences and technical background. Park et al. (2010) recommended taking learning style into consideration when developing wiki assignments. To accommodate learning style, video and audio material as well as written instructions could be used in training and orientations. In addition, to overcome these barriers, prior to the project, students need to be convinced that using wikis to learn and write documents is a worthwhile endeavor. 
One student suggested he preferred discussion forums to wikis. Sharp and Whaley (2018) found students preferred wikis over discussion forums, because they allowed not only comments, but also adding to student responses. Biasutti (2017) compared the usage of forums and wikis in online teaching, showing that discussions promoted inferencing, evaluating, organizing, and supporting while wikis encouraged mainly processes of producing and developing. We recommend using both strategies in online courses.

\section{Conclusion}

This study confirms much of the research on using wikis in the online learning environment. Wikis get students engaged in the learning process. Wikis also encourage student collaboration in knowledge acquisition, suggesting that process may be as important to learning as are the outcomes. The benefits of using wikis for learning are equally important as the final document.

The notion that collaboration leads to learning is reason enough to suggest that instructors and course developers should consider using wikis in online courses. Nevertheless, wikis require students to learn a new skill and step out of the comfort of the more traditional online modalitiespaper writing and discussion forums. Students need to be persuaded of the value of using wikis. Students need to be oriented to the purpose and benefits of using the strategy. This is particularly challenging in the online environment, where students learn by doing. If it does not appear to be related to the topic of their studies, they may resist learning a new instructional approach. In addition, students need to receive instructions about how to use wikis. Also, the software used must make editing the wiki easy and they need to have incentives built into the assignment to make revisions.

While this study appropriately used qualitative methods, it is limited by its sample size (17) and the fact that it only examines one case. The methodology used in this study could be replicated to include more cases and a larger number of participants. In addition, a comparative study of wiki software platforms would be helpful to instructors looking to use wiki in online learning. Also, more information is needed about how to incentivize and motivate students who are using wikis in online courses. 


\section{References}

Abdelmalak, M. M. M. (2014). Web 2.0 technologies and building online learning communities: Students' perspectives. Online Learning, 19(2). http://dx.doi.org/10.24059/olj.v19i2.413

Archambault, P. M., Bilodeau, A., Gagnon, M.-P., Aubin, K., Lavoie, A., Lapointe, J., Poitras, J., Croteau, S., Pham-Dinh, M., \& Légaré, F. (2012). Health care professionals' beliefs about using wiki-based reminders to promote best practices in trauma care. Journal of Medical Internet Research, 14(2), e49. https://doi-org.ezproxy.uvu.edu/10.2196/jmir.1983

Bengtsson, M. (2016). How to plan and perform a qualitative study using content analysis. NursingPlus Open, 2, 8-14. https://doi.org/10.1016/j.npls.2016.01.001

Biasutti, M. (2017). A comparative analysis of forums and wikis as tools for online collaborative learning. Computers \& Education, 111, 158-171.

Bolisani, E., \& Scarso, E. (2016). Factors affecting the use of wiki to manage knowledge in a small company. Journal of Knowledge Management, 20(3), 423-443. https://doiorg.ezproxy.uvu.edu/10.1108/JKM-05-2015-020

Castleberry, A., \& Nolen, A. (2018). Thematic analysis of qualitative research data: Is it as easy as it sounds? Currents in Pharmacy Teaching and Learning, 10, 807-815.

Chu, S. W., Zhang, Y., Chen, K., Chan, C. K., Lee, C. Y., Zou, E., \& Lau, W. (2017). The effectiveness of wikis for project-based learning in different disciplines in higher education. The Internet and Higher Education, 33, 49-60.

Dixson, Marcia D. (2015). Measuring student engagement in the online course: The online student engagement scale (OSE). Online Learning, 19(4), 143-157.

Ertmer, P.A., Newby, T. J., Liu, W., Tomory, A., Yu, J. H., \& Lee, Y. M. (2011). Students' confidence and perceived value for participating in cross-cultural wiki-based collaborations. Educational Technology Research and Development, 59(2), 213-228.

Evans, M. J., \& Moore, J. S. (2011). A collaborative, wiki-based organic chemistry project incorporating free chemistry software on the web. Journal of Chemical Education, 88(6), 764768.

Grace, T. (2009). Wikis as a knowledge management tool. Journal of Knowledge Management, 13(4), 64-74. https://doi-org.ezproxy.uvu.edu/10.1108/13673270910971833

Hasan, H. M., \& Pfaff, C. C. (2006). The Wiki: An environment to revolutionise employees' interaction with corporate knowledge (pp. 377-380). ACM Press. http://ro.uow.edu.au/cgi/viewcontent.cgi?article=3191\&context=commpapers

He, W., \& Yang, L. (2016). Using wikis in team collaboration: A media capability perspective. Information \& Management, 53(7), 846-856. https://doi-org.ezproxy.uvu.edu/10.1016/j.im.2016.06.009

Hewege, C. R., \& Perera, L. C. R. (2013). Pedagogical significance of wikis: Towards gaining effective learning outcomes. Journal of International Education in Business, 6(1), 51-70.

Howe, J. (2008). Crowdsourcing: Why the power of the crowd is driving the future of business. Crown Publishing Group. 
Hu, Q., \& Johnston, E. (2012). Using a wiki-based course design to create a student-centered learning environment: strategies and lessons. Journal of Public Affairs Education, 18(3), 493512.

Hubble, L. (2011). Study strategies \& student engagement using wikis: Collaborative note taking with the Cornell method. Online Learning Consortium. https://secure.onlinelearningconsortium.org/effective_practices/study-strategies-studentengagement-using-wikis-collaborative-note-taking-cornel

Infeld, D. L., \& Adams, W. C. (2013). Wikipedia as a tool for teaching policy analysis and improving public policy content online. Journal of Public Affairs Education, 3, 445.

Kannaley, K., Mehta, S., Yelton, B., \& Friedman, D. B. (2019). Thematic analysis of blog narratives written by people with Alzheimer's disease and other dementias and care partners. Dementia: The International Journal of Social Research and Practice, 18(7-8), 3071-3090.

Kirkwood, A., \& Price, L. (2013). Examining some assumptions and limitations of research on the effects of emerging technologies for teaching and learning in higher education. British Journal of Educational Technology, 44(4), 536-543.

Leal, F., Veloso, B. M., Malheiro, B., González-Vélez, H., \& Burguillo, J. C. (2019). Scalable modelling and recommendation using wiki-based crowdsourced repositories. Electronic Commerce Research \& Applications, 33, 100817.

Li, X., \& Chu, S. K. W. (2018). Using design-based research methodology to develop a pedagogy for teaching and learning of Chinese writing with wiki among Chinese upper primary school students. Computers \& Education, 126, 359-375.

Marx, S. (2008). Rich data. In L. M. Given (Ed.), The sage encyclopedia of qualitative research methods (p. 795).

Morse, J. M. (2015). “Data were saturated...” Qualitative Health Research, 25(5), 587-588. https://doi.org/10.1177/1049732315576699

Ojala, M. (2008). Business Research 2.0. Online, 32(2), 45-47.

Oskoz, A., \& Elola, I. (2014). Promoting foreign language collaborative writing through the use of web 2.0 tools and tasks. In M. González-Lloret \& L. Ortega (Eds.), Technology-mediated TBLT: Researching technology and tasks (pp. 115-147). Benjamins.

Page, K. L., \& Reynolds, N. (2015). Learning from a wiki way of learning. Studies in Higher Education, 40(6), 988-1013.

Palomo-Duarte, M., Dodero, J. M., García-Domínguez, A., Neira-Ayuso, P., Sales-Montes, N., Medina-Bulo, I., Palomo-Lozano, F., Castro-Cabrera, C., Rodríguez-Posada, E. J., \& Balderas, A. (2014). Scalability of assessments of wiki-based learning experiences in higher education. Computers in Human Behavior, 31, 638-650.

Park, C. L., Crocker, C., Nussey, J., Springate, J., \& Hutchings, D. (2010). Evaluation of a teaching tool-wiki-in online graduate education. Journal of Information Systems Education, 21(3), 313-321.

Pew Internet and American Life Report. (2011). Wikipedia, past and present. https://www.pewinternet.org/wpcontent/uploads/sites/9/media/Files/Reports/2011/PIP_Wikipedia.pdf 
Qian, H., \& Erik, J. (2012). Using a wiki-based course design to create a student-centered learning environment: Strategies and lessons. Journal of Public Affairs Education, 3, 493.

Rothman, L. (2016, January 15). Wikipedia at 15: How the concept of a Wiki was invented. Time. http://time.com/4177280/wiki-history-wikipedia/

Rott, S., \& Weber, E. D. (2013). Preparing students to use wiki software as a collaborative learning tool. CALICO Journal, 2, 179.

Roussinos, D., \& Jimoyiannis, A. (2013). Analysis of students' participation patterns and learning presence in a wiki-based project. Educational Media International, 50(4), 306-324.

Sener, J. (2019). CJENCYCLOPEDIA.COM: Online encylopedia of criminal justice. Online Learning Consortium. https://secure.onlinelearningconsortium.org/effective_ practices/cjencyclopediacom-online-encyclopedia-criminal-justice

Sharp, L. A., \& Whaley, B. (2018). Wikis as online collaborative learning experiences: "A different kind of brainstorming." Adult Learning, 29(3), 83-93. https://doi.org/10.1177/1045159518761095

Shih, W. C., Tseng, S. S., \& Yang, C. T. (2008). Wiki-based rapid prototyping for teaching-material design in e-Learning grids. Computers \& Education, 51(3), 1037-1057.

Stoddart, A., Chan, J. Y.-Y., \& Liu, G.-Z. (2016). Enhancing successful outcomes of wiki-based collaborative writing: a state-of-the-art review of facilitation frameworks. Interactive Learning Environments, 24(1), 142-157. https://doi.org/10.1080/10494820.2013.825810

Sykes, J. M., Oskoz, A., \& Thorne, S. L. (2008). Web 2.0, synthetic immersive environments, and mobile resources for Language Education. CALICO Journal, 25(3), 528-546. http://www.jstor.org/stable/calicojournal.25.3.528

Trocky, N. M. \& Buckley, K. M. (2016). Evaluating the impact of wikis on student learning outcomes: An integrative review. Journal of Professional Nursing, 32, 364-376. https://doi:10.1016/j.profnurs.2016.01.007

Wickler, G., Tate, A., \& Hansberger, J. (2013). Using shared procedural knowledge for virtual collaboration support in emergency response. IEEE Intelligent Systems, 28(4), 9-17.

Woolley, S., \& Ludwig-Hardman, S. (2000). Online learning communities: Vehicles for collaboration in Online Learning Environments. In J. Bourdeau \& R. Heller (Eds.), Proceedings of ED-MEDIA 2000 — World Conference on Educational Multimedia, Hypermedia \& Telecommunications (pp. 1835-1836). Association for the Advancement of Computing in Education (AACE). https://www.learntechlib.org/primary/p/16623/

Yarbrough, J. R. (2018). Wiki based dynamic quizzes: A bridge between online students and instructors? Journal of Instructional Pedagogies, 20.

Zgheib, G., \& Dabbagh, N. (2020). Social media learning activities (SMLA): Implications for design. Online Learning, 24(1). http://dx.doi.org/10.24059/olj.v24i1.1967

Zou, B., Wang, D., \& Xing, M. (2016). Collaborative tasks in wiki-based environment in EFL learning. Computer Assisted Language Learning, 29(5), 1000-1016. https://doi:10.1080/09588221.2015.1121878 